\title{
QUALIDADE DE MUDAS DE MANJERICÃO (Ocimum basilicum L.) EM CASA DE VEGETAÇÃO SUBMETIDA A DIFERENTES SUBSTRATOS E CONCENTRAÇÃO DE ÁCIDO INDOLBUTIÍRICO
}

\author{
João Paulo Francisco* \\ Jefferson Vieira José** \\ Irineu Pedro de Sousa Andrade*** \\ Marcos Vinicius Folegatti*** \\ Patrícia Angelica Alves Marques*****
}

RESUMO: O presente trabalho foi conduzido no Departamento de Engenharia de Biossistemas da ESALQ/USP, durante o período de agosto a setembro de 2013 . O experimento avaliou três tipos de substratos (areia lavada, fibra de coco e substrato Plantmax®) e cinco diferentes concentrações de ácido indolbutírico (AIB - 0, 500, 1000,2000 e $4000 \mathrm{mg} \mathrm{L}^{-1}$ ). O delineamento experimental adotado foi o fatorial inteiramente aleatorizado 3 x 5, com quatro repetições. Os efeitos principais da interação multiplicativa, modelo AMMI, do substrato (S) e AIB (A) foram utilizados para analisar as variáveis biométricas. Os fatores substrato (S) e a interação $S \times$ A foram significativos para massa seca de folhas e raízes, comprimento radicular, diâmetro do caule, razão diâmetro-altura e índice de qualidade de Dickson. O teste de Gollob apresentou um componente principal significativo (IPCA1). A estaquia de Ocimum basilicum L. pode ser realizada tanto por substrato Plantmax ${ }^{\circledR}$ sem tratamento de ácido indolbutírico, como pelo substrato areia lavada com o tratamento de ácido indolbutírico na concentração de $2000 \mathrm{mg} \mathrm{L}^{-1}$.

PALAVRAS-CHAVE: Enraizamento; Estaquia; Modelo AMMI.

\footnotetext{
"Eng. ${ }^{\circ}$ Agrônomo, mestre em Engenharia de Sistemas Agrícolas doutorando em Engenharia de Sistemas Agrícolas, Departamento de Engenharia de Biossistemas, Escola Superior de Agricultura "Luiz de Queiroz" - USP

${ }^{* *}$ Eng. ${ }^{\circ}$ Agrícola, Mestre em Agronomia e Doutorando de Engenharia de Sistemas Agrícolas pela Universidade de São Paulo - ESALQ/USP; E-mail: jfvieira@usp.br

**** Eng. ${ }^{\circ}$ Agrônomo; doutorando em Engenharia de Sistemas Agrícolas, Departamento de Engenharia de Biossistemas, Escola Superior de Agricultura "Luiz de Queiroz" - USP

***** Eng. ${ }^{\circ}$ Agrônomo, doutor em Irrigação e Drenagem, Departamento de Engenharia de Biossistemas - Engenharia de Sistemas Agrícolas, Escola Superior de Agricultura "Luiz de Queiroz" - USP

****** Eng. a Agrônoma, doutora em Irrigação e Drenagem, Departamento de Engenharia de Biossistemas - Engenharia de Sistemas Agrícolas, Escola Superior de Agricultura "Luiz de Queiroz" - USP
} 


\title{
QUALIT Y OF BASIL SEEDLINGS (Ocimum basilicum L.) IN A GREENHOUSE, WITH DIFFERENT SUBSTRATES AND CONCENTRATIONS OF INDOLBUTIRIC ACID
}

\begin{abstract}
Current assay, conducted at the Department of Biosystem Engineering of ESALQ/USP between August and September 2013, evaluated three types of substrates (washed sand, coconut fiber and Plantmax $®$ ) and five different concentrations of indolbutiric acid (AIB - 0, 500, 1000, 2000 and $4000 \mathrm{mg} \mathrm{L}^{-1}$ ). The randomized 3 x 5 experimental design was employed, with four replications. The main effects of multiplicative interaction, AMMI model, of substrate (S) and AIB (A) analyzed the biometric variables. Factors substrate (S) and interaction $S \times$ A were significant for dry mass of leaves and roots, root length, stem diameter, diameter-height ratio and Dickson's quality index. Gollob's test provided a significant main component (IPCA1) and the cutting of Ocimum basilicum L. may be done either with substrate Plantmax ${ }^{\circledR}$ without indolbutiric acid treatment and by washed sand treatment with indolbutiric acid treatment at concentration $2000 \mathrm{mg} \mathrm{L}^{-1}$.
\end{abstract}

KEY WORDS: Rooting; Cutting; AMMI Model.

\section{INTRODUÇÃO}

O manjericão (Ocimum basilicum L.), pertencente à família Laminaceae, é uma planta medicinal, aromática e condimentar com elevada importância no cenário econômico mundial. Apesar de o manjericão ser cultivado principalmente por pequenos produtores, a grande possibilidade de exploração das espécies de Ocimun como planta medicinal tem estimulado uma série de pesquisas envolvendo aspectos agronômicos na produção de mudas destas plantas, principalmente no que se refere às técnicas de cultivo na produção, rendimento e composição do óleo essencial (BRANT et al., 2009).

De acordo com Telma (2011), o processo de propagação da espécie ainda é deficiente, pois é preciso aprimorar técnicas de enraizamento espontâneo para que ocorra um aumento no desenvolvimento da cadeia produtiva de plantas medicinais no Brasil. As espécies do gênero Ocimun apresentam facilidade à hibridização, ou seja, novas populações podem ser obtidas por cruzamentos interespecíficos, 
possibilitando um aumento da variabilidade a ser selecionada obtida a partir das sementes, mantendo as características favoráveis.

$\mathrm{Na}$ produção destas espécies é muito importante a obtenção de matériaprima em quantidade e qualidade desejadas. Para isso, deve-se tentar diminuir a interferência dos fatores ambientais, técnicos e a variabilidade química natural das espécies, portanto a propagação vegetativa se torna muito importante, principalmente pela uniformidade das mudas produzidas (CUNHA et al., 2013).

Segundo Hartmann et al. (2002), a estaquia é uma forma de propagação vegetativa assexuada ou agâmica das plantas, através de seus órgãos vegetativos. Além disso, apresenta várias vantagens, permitindo a clonagem de plantas superiores em produtividade, uniformidade e qualidade de frutos ou folhas; a seleção e manutenção de plantas de maior resistência a doenças e pragas; a propagação de plantas que não produzam sementes; assim como possibilita a antecipação do período produtivo, sendo a técnica mais utilizada na produção comercial de diversas espécies na horticultura.

Para Ocimun o método de propagação mais recomendado é o da estaquia, que é o termo utilizado para designar o método de propagação no qual um segmento da planta matriz é retirado, colocado em condições ambientais favoráveis e induzido a formar raízes e brotos, obtendo-se uma nova planta (FACHINELLO; HOFFMANN; NACHTIGAL, 2005).

A formação de mudas relaciona-se diretamente com a eficiência do substrato, dessa forma a composição dos mesmos vem sendo alvo das pesquisas, visando obtenção de meios de crescimentos que apresentem composição uniforme, baixa densidade, alta capacidade de retenção de água, boa aeração e drenagem, proporcionando condições ideais para o crescimento e desenvolvimento das mudas (MOURA et al., 2009). Por outro lado, pesquisas recentes com propagação vegetativa de espécies medicinais como Ocimum gratissimum (EHLERT; LUZ; INNECCO, 2004) não encontraram diferenças significativas no enraizamento com os substratos testados. Portanto, estudos com diferentes substratos para o cultivo de manjericão são de fundamental importância para produção de mudas por estaquia.

De acordo com Fachinello, Hoffmann e Nachtigal (2005), a formação de raízes em estacas pode ser limitada pelo substrato utilizado, uma vez que este 
influi na qualidade das raízes e no percentual de enraizamento. No entanto, o aumento da capacidade de enraizamento pode ser alcançado por meio da utilização de reguladores de crescimento. As auxinas são os reguladores de crescimento mais utilizados para favorecer o processo de formação de raízes, sendo o ácido indolbutírico (AIB) a principal auxina sintética utilizada, porque não é tóxica para a maioria das plantas, mesmo em altas concentrações; é bastante efetiva para um grande número de espécies e relativamente estável, sendo pouco suscetível à ação dos sistemas de enzimas de degradação de auxinas (PIRES; BIASI, 2003).

Trabalhos relacionados com propagação vegetativa de espécies medicinais ainda são escassos, principalmente no caso de Ocimum basilicum L. Diante do exposto, o objetivo do trabalho foi avaliar o efeito de diferentes concentrações de AIB no enraizamento de estacas de Ocimum basilicum L. em substrato comercial, areia lavada e fibra de coco.

\section{MATERIAL E MÉTODOS}

O experimento foi conduzido na área experimental do Departamento de Engenharia de Biossistemas, da Escola Superior de Agricultura "Luiz de Queiroz", vinculada à Universidade de São Paulo (USP) e situada no município de Piracicaba (SP), nas coordenadas geográficas de 22 42' 40" de latitude Sul; $47^{\circ} 37^{\prime}$ 45" de longitude Oeste; e 547 metros de altitude, no período de agosto a setembro de 2013 .

O experimento foi realizado em casa de vegetação, com estrutura metálica galvanizada, medindo 6,4 m de altura na parte central, 12,8 $\mathrm{m}$ de largura, 22,5 m de comprimento e com janelas frontais. A cobertura consistia de filme de polietileno transparente de baixa densidade, com espessura de $0,15 \mathrm{~mm}$. O monitoramento meteorológico foi realizado com sensores de radiação global, temperatura e umidade relativa do ar.

O delineamento experimental adotado foi o inteiramente aleatorizado em esquema fatorial $3 \times 5$, com cinco repetições, totalizando 75 unidades experimentais. A unidade experimental foi constituída de tubetes com volume de $120 \mathrm{~cm}^{3}$. Os 
tratamentos corresponderam à combinação de três substratos (areia lavada, fibra de coco e substrato Plantmax ${ }^{\circledR}$ ) com cinco níveis de ácido indolbutírico (AIB), cujas concentrações na solução foram de 0, 500, 1000, 2000 e $4000 \mathrm{mg} \mathrm{L}^{-1}$.

As plantas de Ocimum basilicum L. utilizadas foram propagadas sexuadamente, com aproximadamente 1,5 anos de idade (seis colheitas), cultivadas individualmente em vaso plástico contendo 15 litros, em um Nitossolo Vermelho distroférrico. As mudas foram obtidas a partir de plantas matrizes fornecidas pela empresa LINAX Comércio de Óleos Essenciais LTDA, situada no município de Votuporanga (SP). Selecionaram-se estacas (caule herbáceo) da parte apical dos ramos principais, a fim de uniformizar os diâmetros, e que tivessem brotos ou gemas axilares fisiologicamente ativos, com a presença de folhas (MATTANA et al., 2009).

As estacas selecionadas foram cortadas em bisel e acondicionadas em um recipiente contendo água destilada. As bases de cada estaca foram imersas por 10 segundos em solução aquosa de AIB previamente dissolvida em hidróxido de sódio $1 \mathrm{~mol} \mathrm{~L}^{-1} \mathrm{e}$ água destilada a fim de se obter as concentrações de $0,500,1000,2000 \mathrm{e}$ $4000 \mathrm{mg} \mathrm{L}^{-1}$. Após imersão, as estacas foram inseridas em tubetes preenchidos com os devidos substratos. Os tubetes foram previamente desinfetados com solução de água sanitária a 5\%. A irrigação das estacas procedeu-se diariamente, com a frequência de duas vezes por dia.

A avaliação foi realizada aos 21 dias após a estaquia (DAE). As plantas selecionadas foram retiradas dos tubetes e seccionadas na região do colo, separando a parte radicular da parte aérea. A parte radicular foi lavada sobre peneira com malha de $2 \mathrm{~mm}$, visando à retirada do substrato. Em seguida, as raízes foram colocadas em bandejas de plástico durante 2 horas para remoção do excesso de água. As partes aéreas e radiculares das plantas foram acondicionadas separadamente em embalagens de papel, identificadas e secas em estufa de ventilação forçada a $65^{\circ} \mathrm{C}$, onde o material foi mantido até atingir o peso seco constante, medido posteriormente em balança digital de precisão de $\pm 0,0001 \mathrm{~g}$.

As variáveis analisadas foram as seguintes: porcentagem de estacas enraizadas (\%ENR); comprimento do sistema radicular (CRAIZ); diâmetro do caule (DIAM); matéria seca da parte aérea (MSA) e da raiz (MSRAIZ); e Índice de Qualidade de Dickson (IQD), determinado por meio da Eq. (1). 


$$
\mathrm{IQD}=\frac{\mathrm{MST}}{\mathrm{RAD}+\mathrm{RMS}}
$$

em que:

IQD: índice de qualidade de Dickson;

MST: massa seca total, g;

RAD: razão altura-diâmetro, $\mathrm{cm} \mathrm{mm}^{-1}$;

RMS: razão de massa seca da parte aérea pela raiz, adimensional.

As leituras do diâmetro do caule foram realizadas com auxílio de um paquímetro digital de precisão, medido em escala milimétrica a $0,01 \mathrm{~m}$ do nível do substrato. Para a porcentagem de estacas vivas considerou-se apenas as estacas vivas que tinham emitido o primórdio radicular.

Inicialmente, os dados experimentais foram submetidos aos testes de Shapiro-Wilk $(\mathrm{P}>0,01)$ e de Levene $(\mathrm{P}>0,01)$, para verificação da normalidade e homocedasticidade residuais, respectivamente, e posteriormente realizou-se a análise de variância (individual). Observada a diferença significativa da interação substrato com AIB, procedeu-se a análise de estabilidade (conjunta), por meio do modelo de interação multiplicativa, conhecida como modelo AMMI (Additive main effect sand multiplicative interaction):

$$
Y_{i j}=\mu+S_{i}+A_{j}+\sum_{k=1}^{n} \lambda_{k} \gamma_{i k} \alpha_{i k+} \rho_{i j+} e_{(i I) j}
$$

Em que:

$\mathrm{Y}_{\mathrm{ij}}$ é a resposta média do substrato $\mathrm{i}(\mathrm{i}=1,2$ e $3, \mathrm{~S}$ substratos) na dose de AIB j ( $j=1,2,3,4$ e 5, A, AIB); m é a média geral dos ensaios; Si é o efeito fixo do substrato i; Aj é o efeito fixo do AIB j; $1_{\mathrm{k}}$ é o k-ésimo singular (escalar) da matriz de interações original (SxA); $\mathrm{g}_{\mathrm{ik}}$ é o elemento correspondente ao i-ésimo substrato no k-ésimo vetor singular coluna da matriz $S x A ; a_{j k}$ é o elemento correspondente ao j-ésimo ambiente no k-ésimo vetor singular linha da matriz SxA; $\mathrm{r}_{\mathrm{ij}}$ é o ruído associado ao termo (SxA)ij da interação clássica do substrato com o AIB j; e(il) j é o erro experimental médio. 
Os resultados foram representados na forma gráfica de um biplot (GABRIEL, 1971), que são representações das coordenadas dos substratos e dos AIB nos eixos principais de interação (IPACs). O nível de significância de IPCA foi testado com o teste F de acordo com Gollob (1968).

Às variáveis que não foram observadas diferenças significativas do IPAC procedeu-se a análise de variância com os resultados comparados pelo teste de Scott-Knott $(\mathrm{P}>0,05)$. As análises foram realizadas com o auxílio do R, versão 2.2.1 (R. DEVELOPMENT CORE TEAM, 2013), utilizou-se a macro AMMI (livre) conforme descrito por Lavoranti (2004).

\section{RESULTADOS E DISCUSSÃO}

As variações das temperaturas máxima (Tmax) e mínima (Tmin), bem como as umidades relativas máxima (URmax) e mínima (URmin), registradas no período do experimento são apresentadas na Figura 1 . A Tmax variou de 13 a $23{ }^{\circ} \mathrm{C}$; a Tmin variou de 5 a $15{ }^{\circ} \mathrm{C}$; URmax e URmin variaram de 79 a 93\% e 13 a 62\%, respectivamente. A maior amplitude térmica registrada na casa de vegetação foi de $27^{\circ} \mathrm{C}$ aos 16 DAE.

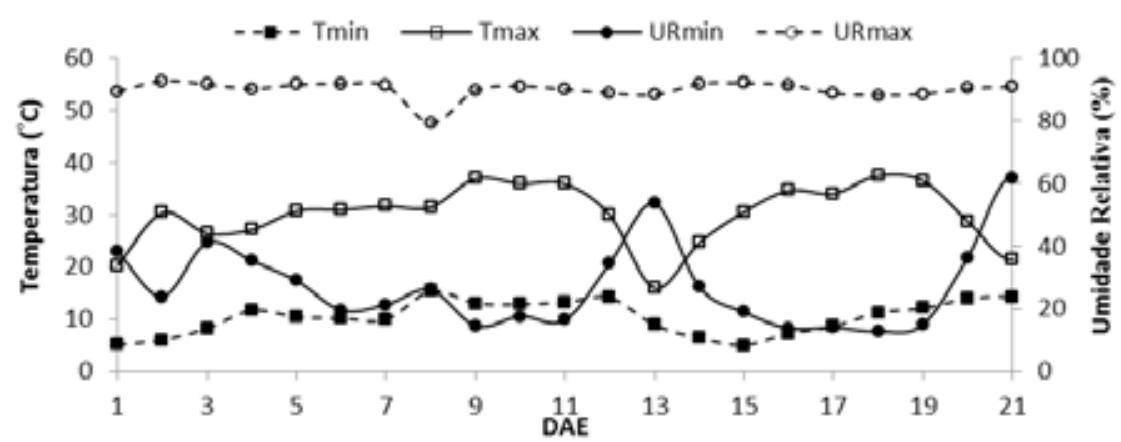

Figura 1. Variação da temperatura mínima e máxima (Tmin e Tmax) e a umidade relativa do ar (URmin e URmax) nos 21 dias após estaquia (DAE).

Segundo Pacheco (2007), a iniciação do enraizamento é comandada principalmente pela temperatura e maiores estímulos de desenvolvimento de raízes 
em estacas herbáceas são verificados quando as temperaturas diurnas se encontram entre 23 e $27^{\circ} \mathrm{C}$, com temperaturas noturnas em torno de $15^{\circ} \mathrm{C}$. Verifica-se que as temperaturas observadas neste trabalho se encontraram abaixo das temperaturas recomendadas por outros autores; no entanto, quando submetidas a baixas temperaturas, estacas herbáceas têm sua respiração reduzida, o que permite uma melhor acumulação fotossintética para o desenvolvimento das raízes (HARTMANN et al., 2002). Pacheco (2007) refere, ainda, que a umidade relativa do ambiente deve ser mantida entre os 80 e $100 \%$, evitando-se, assim, a perda das folhas.

De acordo com a análise das propriedades físicas dos substratos (Tabela 1), a fibra de coco apresentou maior porosidade (79\%) e a menor retenção hídrica (23\%). O desenvolvimento da muda depende das propriedades físicas, químicas e biológicas do substrato que a sustenta, o que interfere diretamente na qualidade (LOURENÇO et al., 1999). Uma boa aeração do substrato é uma das principais características físicas para o crescimento de plantas em recipientes; desta forma, não somente a água é necessária para as plantas, mas também o ar é importante para o crescimento radicular. Milner (2002) afirma que a porosidade total ideal para substratos está em torno de 70 a 85\%. Ao utilizar um substrato com baixa densidade e alta porosidade há o favorecimento equilibrado entre a aeração e a retenção de umidade.

Tabela 1. Densidade das partículas ( $\rho p)$, densidade global $(\rho g)$, porosidade $(\mathrm{P})$, retenção hídrica (RH) e espaço de aeração dos tubetes (EA) dos substratos.

\begin{tabular}{lccccc}
\multicolumn{1}{c}{ Substratos } & pp & pg & P & RH & EA \\
\hline & \multicolumn{2}{c}{$\mathbf{g ~ c m}^{-3}$} & \multicolumn{4}{c}{$\%$} \\
\cline { 2 - 6 } S1 - Plantmax & $0,95 \pm 0,04$ & $0,35 \pm 0,02$ & $63,37 \pm 1,33$ & $41,30 \pm 0,93$ & $22,07 \pm 1,22$ \\
S2 - Areia lavada & $2,75 \pm 0,01$ & $1,74 \pm 0,06$ & $36,95 \pm 1,61$ & $33,22 \pm 0,30$ & $3,73 \pm 1,56$ \\
S3 - Fibra de coco & $0,48 \pm 0,05$ & $0,10 \pm 0,05$ & $79,58 \pm 1,95$ & $23,46 \pm 0,52$ & $56,13 \pm 2,03$ \\
\hline
\end{tabular}

Os resultados da análise de variância individual para cada variável apresentaram diferenças significativas para a fonte de variação de substrato e a interação entre substrato e AIB, exceto para o fator AIB, sendo não significativa, isto é, o efeito dos substratos foi responsável pela maior parte da variação dos tratamentos, seguido pelo efeito da interação. 
A interação significativa indicou que os tipos de substratos sofreram influências diferenciadas das concentrações de AIB, ou seja, responderam de forma diferente aos estímulos de AIB. Assim, para este efeito, a análise foi diagnosticada pelo teste $\mathrm{F}$ de Gollob, conforme dados apresentados na Tabela 2. A análise da interação dos componentes principais apresentou significância para IPCA nas variáveis estudadas com exceção da porcentagem de estacas enraizadas.

Tabela 2. Análise da Variância Individual e Conjunta de Gollob (1968), incluindo o desdobramento da interação, entre os três substratos nas cinco concentrações de AIB para as estacas de Ocimum basilicum $\mathrm{L}$.

\begin{tabular}{cccccc}
\hline \multirow{2}{*}{ Fator de variância } & G.L. & \%ENR & DIA & RAD & CRAIZ \\
\cline { 3 - 6 } & & \multicolumn{4}{c}{ Quadrado médio do resíduo } \\
\hline Substrato (S) & 2 & $3840^{* *}$ & $0,882372^{*}$ & $0,316446^{*}$ & $0,011063^{* *}$ \\
AIB (A) & 4 & $240^{\text {ns }}$ & $0,137096^{\text {ns }}$ & $0,00434^{\text {ns }}$ & $0,000076^{\text {ns }}$ \\
\hline S x A & 8 & $240^{* *}$ & $0,157705^{* *}$ & $0,009138^{*}$ & $0,000530^{* *}$ \\
\hline IPCA1 & 5 & $0,20^{\text {ns }}$ & $0,251060^{* *}$ & $0,011893^{*}$ & $0,000734^{* *}$ \\
IPCA2 & 3 & $0,33^{\text {ns }}$ & $0,072800^{\text {ns }}$ & $0,00454^{\text {ns }}$ & $0,000468^{\text {ns }}$ \\
\hline Erro Médio & 48 & 44,16 & 0,029022 & 0,080722 & 0,000129 \\
\hline
\end{tabular}

G.L. - Grau de liberdade; Q.M. - Quadrado médio do resíduo; AIB - Ácido indolbutírico; ** - significativo ao nível de probabilidade, $\mathrm{p}<0,01 ;{ }^{*}$ - significativo ao nível de probabilidade, $\mathrm{p}<0,05$; $^{\text {ns }}$ -não significativo.

Como não houve efeito significativo no IPCA, para a variável porcentagem de estacas enraizadas, procedeu-se ao teste de média de Scott-Knott, conforme dados da Tabela 3. Não houve diferenças entre as concentrações de AIB nos substratos Plantmax ${ }^{\circledR}$ e areia lavada, porém o substrato fibra de coco diferiu nas concentrações de AIB, sendo a concentração de 500 e $1000 \mathrm{mg} \mathrm{L}^{-1}$ as que apresentaram as maiores porcentagens de estacas enraizadas (80\%). 
Tabela 3. Porcentagem de estacas enraizadas na propagação vegetativa de Ocimum basilicum L., em função dos substratos e das concentrações de ácido indolbutírico.

\begin{tabular}{|c|c|c|c|c|c|c|}
\hline \multirow[b]{2}{*}{ Substrato } & \multicolumn{6}{|c|}{ Ácido indolbutírico - AIB } \\
\hline & Média & $\begin{array}{c}\text { AIB } 1 \\
0 \mathrm{mg} \mathrm{L}^{-1}\end{array}$ & $\begin{array}{c}\text { AIB } 2 \\
500 \mathrm{mg} \mathrm{L}^{-1}\end{array}$ & $\begin{array}{c}\text { AIB 3 } \\
1000 \mathrm{mg} \mathrm{L}^{-1}\end{array}$ & $\begin{array}{c}\text { AIB 4 } \\
2000 \mathrm{mg} \mathrm{L}^{-1}\end{array}$ & $\begin{array}{c}\text { AIB } 5 \\
4000 \mathrm{mg} \mathrm{L}^{-1}\end{array}$ \\
\hline Sub 1 - Plantmax ${ }^{\circledR}$ & $100 \mathrm{a}$ & $100 \mathrm{aA}$ & $100 \mathrm{aA}$ & $100 \mathrm{aA}$ & $100 \mathrm{aA}$ & $100 \mathrm{aA}$ \\
\hline Sub 2 - Areia lavada & $100 \mathrm{a}$ & $100 \mathrm{aA}$ & $100 \mathrm{aA}$ & $100 \mathrm{aA}$ & $100 \mathrm{aA}$ & $100 \mathrm{aA}$ \\
\hline $\begin{array}{l}\text { Sub } 3 \text { - Fibra de } \\
\text { coco }\end{array}$ & $52 \mathrm{~b}$ & $40 \mathrm{bB}$ & $80 \mathrm{bA}$ & $80 \mathrm{bA}$ & $40 \mathrm{bB}$ & $20 \mathrm{bC}$ \\
\hline
\end{tabular}

Médias seguidas da mesma letra minúscula na coluna e na linha maiúscula não diferem entre si, conforme teste de Scott-Knott ao nível de 0,05 de probabilidade.

No fator substrato, observa-se que as estacas de Ocimum basilicum L. que apresentaram maior porcentagem de estacas enraizadas foram os substratos Plantmax $^{\circledR}$ e areia lavada (100\%), a fibra de coco obteve $52 \%$ de sobrevivência. Verificou-se durante a condução do trabalho que a sustentação das estacas no substrato fibra de coco era deficiente; desta forma, a alta porosidade da fibra de coco (Tabela 1), aliada ao baixo valor de diâmetro das estacas (Figura 2), podem ter proporcionado um aumento na luminosidade na base das estacas e uma aeração excessiva; desta forma, houve um escurecimento de sua base, impossibilitando a desdiferenciação das células dos tecidos e impedindo o surgimento dos primórdios radiculares. Destaca-se a rápida queda das folhas das estacas sustentadas no substrato fibra de coco, possivelmente pela ativação de mecanismos de síntese de etileno (TAIZ; ZEIGER, 2009). A senescência das folhas pode ter suspendido a síntese de auxina endógena, impedindo o enraizamento e provocando a morte das estacas.

Os dados de variáveis DIAM, RAD e CRAIZ, conforme exposto, foram avaliados pelo modelo AMMI e são apresentados por biplot, na Figura 2. No biplot a abscissa representa os efeitos principais (médias de substratos e de AIB) e a ordenada, o primeiro eixo de interação (IPCA $)$. Assim, substratos com valores de IPCA ${ }_{1}$ próximos a zero demonstram estabilidade aos AIB; combinações de substratos e AIB com escores IPCA de mesmo sinal têm interações específicas positivas; e combinações de sinais opostos apresentam interações específicas negativas.

No biplot dos tipos de substratos e doses de AIB que mais contribuíram para o efeito da interação situam-se distantes de zero, em relação ao eixo IPCA, de 
acordo com Lavoranti (2004). Desta forma, a interação que atende esta situação foi o substrato Plantmax ${ }^{\circledR}$ e AIB4, indicando assim o cruzamento desses fatores como o de maior valor de CRAIZ e DIAM. Para a variável RAD a melhor interação foi a do substrato Plantmax ${ }^{\circledR}$ e AIB5.

Quando se visa a produção de mudas em escala comercial, a emissão de raízes em maior número e comprimento é fator preponderante na constituição de um estande de plantas homogêneo, pois um sistema radicular bem formado favorece a absorção de nutrientes e água permitindo, desta forma, um melhor desenvolvimento da muda no campo.
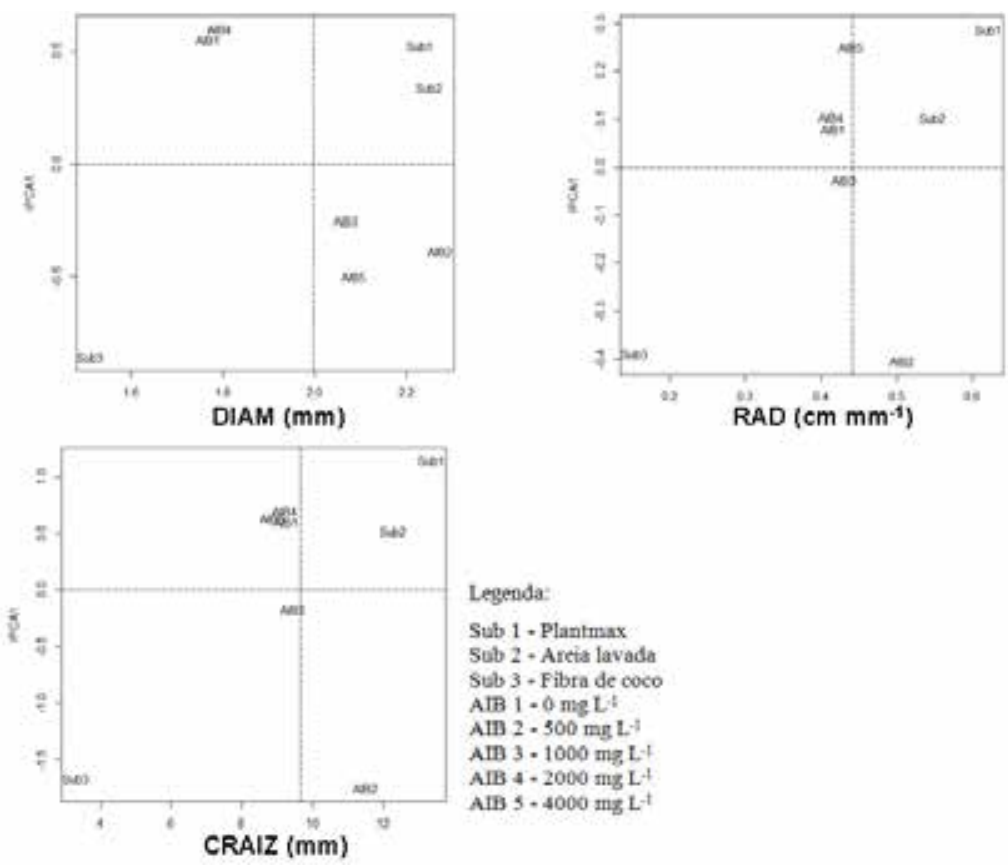

Legenda:

Sub 1 - Plantmax

Sub 2 - Areta lavada

Sub 3 - Fibra de coco

AIB $1.0 \mathrm{mg} \mathrm{L}^{4}$

All $2.300 \mathrm{mg} \mathrm{L}$.

AIB $3 \cdot 1000 \mathrm{mg} \mathrm{L}$.

AlB $4 \cdot 2000 \mathrm{mg} \mathrm{L}$

AfI $5.4000 \mathrm{mg} \mathrm{L}^{-1}$

Figura 2. Biplot AMMI1 para dados de variáveis DIAM, RAD e CRAIZ, com três substratos (Sub) e cinco níveis de concentrações de ácido indolbutírico (AIB) no Ocimum basilicum L.

Ao se analisar as variáveis que definem a qualidade da muda formada, como o comprimento das raízes (COSTA; PINTO; BERTOLUCCI, 2007), observa-se maior valor com o substrato Plantmax ${ }^{\circledR}$ (Figura 2); essa superioridade na emissão de raiz pode ser explicada pelas propriedades físicas desse substrato quando comparado aos demais. Verificou-se que o Plantmax $^{\circledR}$ apresentou elevada porosidade e 
espaço aéreo, possibilitando uma maior retenção hídrica, bem como baixa densidade. Substratos com baixa densidade apresentam uma maior porcentagem de macroporos, dessa forma ocorre um melhor escoamento do excesso de água e favorece o desenvolvimento radicular (MAUAD, 2004).

Foi verificado que a interação entre os fatores substratos e AIB foi significativa para as variáveis estudadas. Segundo Dutra, Kersten e Fachinello (2002), o tratamento de estacas com AIB influencia na qualidade e quantidade de raízes produzidas. Hartmann et al. (2002) afirmaram que o AIB estimula as plantas a produzirem raízes maiores, mais fortes e mais fibrosas. Em experimento com estacas de pessegueiro, Cardoso et al. (2011) observaram diferenças nas concentrações do AIB (0, 1000 e $2000 \mathrm{mg} \mathrm{L}^{-1}$ ) e nos substratos (areia, vermiculita e casca de arroz carbonizada) quanto à porcentagem de enraizamento das estacas.

As concentrações de AIB 4000, 2000, 500 e $0 \mathrm{mg} \mathrm{L}^{-1}$ (Figura 2) foram as que proporcionaram maior comprimento de raízes. Ressalta-se que as estacas utilizadas neste estudo foram retiradas da região apical dos ramos principais com presença de folhas. Estacas apicais apresentam um nível elevado de auxina endógena, bem como as folhas são sítios de síntese de auxinas, carboidratos e cofatores do enraizamento (TAIZ; ZEIGER, 2009). Desta forma, o aumento no comprimento de raízes, mesmo com uso de baixa ou nenhuma concentração de AIB, pode ter ocorrido devido à síntese de auxina endógena nas folhas das estacas, sendo estas suficientes para estimular o enraizamento das estacas. Resultados semelhantes foram encontrados por Bordin et al. (2005) que, ao utilizarem estacas apicais de videira com folhas novas, verificaram que a utilização de auxina exógena (AIB) é dispensável, devido ao fato de a auxina endógena produzida pelas folhas ser suficiente para iniciar o processo de enraizamento destas estacas.

Os dados da análise de variância individual e conjunta dos dados de MSRAIZ, MSPA, RMS e IQD, são apresentados na Tabela 4. Por esta Tabela, percebe-se que os efeitos de substratos, AIB e interação substratos x AIB são significativos. Apresentase, também na Tabela 4, o teste Gollob para determinar o número de componentes adequado para explicar a soma do quadrado médio do resíduo da interação ( $\mathrm{S} \times \mathrm{A}$ ). Portanto, nota-se que o IPCA 1 é o melhor modelo verificado pela significância.

A significância do IPCA 1 está relacionada com as magnitudes dos escores para substratos e para AIB, explicando assim, parte da variação da interação. Pelos 
valores encontrados, pode-se inferir que há padrões de interação diferenciados de substratos e AIB. A resposta esperada para os substratos pode ser identificada pela variabilidade nas variáveis estudadas e pelos valores dos escores do primeiro componente principal um, ( IPCA $_{1}$ ) Escores altos, não importando se positivos ou negativos, indicam grandes interações, ou seja, baixa estabilidade. Por outro lado, escores próximos a zero, refletem baixas interações, acarretando, consequentemente, alta estabilidade (BADU-APRAKU et al., 2012).

Nesse sentido, constatou-se que a amplitude de variação dos escores foi alta para a maioria das variáveis, atribuindo aos substratos os seus maiores valores. Esses altos valores para substratos indicam que eles apresentaram níveis de produtividades bem distintos. O substrato fibra de coco foi o que apresentou o menor IQD, devido à sua alta porosidade pelos motivos mencionados anteriormente.

Tabela 4. Análise da Variância Individual e Conjunta de Gollob (1968), incluindo o desdobramento da interação, entre os três substratos nas cinco concentrações de AIB para as estacas de Ocimum basilicum L.

\begin{tabular}{cccccc}
\hline \multirow{2}{*}{ Fator de variância } & \multirow{2}{*}{ G.L. } & MSRAIZ & MSPA & RMS & IQD \\
\cline { 3 - 6 } & & \multicolumn{5}{c}{ Quadrado médio do resíduo } \\
\hline Substrato (S) & 2 & $0,009912^{*}$ & $0,00267^{* *}$ & $2,23975^{*}$ & $0,638628^{* *}$ \\
AIB (A) & 4 & $0,001241^{\text {ns }}$ & $0,000241^{\text {ns }}$ & $0,356804^{\text {ns }}$ & $0,023384^{*}$ \\
\hline S x A & 8 & $0,001302^{* *}$ & $0,000118^{* *}$ & $0,441569^{* *}$ & $0,006077^{* *}$ \\
\hline IPCA $_{1}$ & 5 & $0,001932^{* *}$ & $0,000173^{*}$ & $0,441469^{* *}$ & $0,008839^{* *}$ \\
IPCA $_{2}$ & 3 & $0,000253^{\text {ns }}$ & $0,000028^{\text {ns }}$ & $0,218375^{\text {ns }}$ & $0,001475^{\text {ns }}$ \\
\hline Erro Médio & 48 & 0,000240 & 0,000124 & 0,000254 & 0,001118 \\
\hline
\end{tabular}

G.L. - Grau de liberdade; Q.M. - Quadrado médio do resíduo; AIB - Ácido indolbutírico; ** - significativo ao nível de probabilidade, $\mathrm{p}<0,01 ;{ }^{*}$ - significativo ao nível de probabilidade, $\mathrm{p}<0,05$; ${ }^{\text {ns }}$ - não significativo.

Os substratos que mais contribuíram para a interação $\mathrm{S} \times \mathrm{A}$ foram os substratos Plantmax ${ }^{\circledR}$ e a fibra de coco, pois apresentaram as maiores magnitudes de escore no eixo de interação (Figura 3). Além disso, o substrato Plantmax ${ }^{\circledR}$ e fibra de coco mostraram interação específica aos AIB 4000, 500 e $0 \mathrm{mg} \mathrm{L}^{-1}$.

Por sua vez, o substrato que menos contribuiu para a interação S x A (mais estáveis) foi o substrato areia lavada e a concentração AIB 3 (menores coordenadas 
para o eixo IPCA), porém estes apresentaram a relação entre a massa seca da parte aérea e do sistema radicular (RMS) acima da média. No entanto, a relação RMS apesar de ser considerado um bom índice para se avaliar a qualidade de mudas, não reflete em uniformidade no crescimento das mudas no campo, sendo muitas vezes preterido em relação a outros (GOMES, 2001).

De acordo com Gomes et al. (2002), o melhor parâmetro para se estimar o crescimento inicial das mudas no campo é o peso da matéria seca das raízes. Verificase na Figura 3 que a interação do substrato areia lavada com o AIB $2000 \mathrm{mg} \mathrm{L}^{-1}$ resultou em maior massa seca de raiz. Mesmo a areia apresentando alta densidade, a água é facilmente drenada, fato este que favorece ao crescimento e distribuição do sistema de raízes, portanto a baixa porosidade deste substrato não prejudicou o crescimento radicular.

Resultados contrastantes com relação ao substrato foram encontrados por Paulus et al. (2011) que, ao avaliarem o efeito de substratos, entre eles a areia, sobre o enraizamento de estacas de Mentha arvensis L., verificaram resultados superiores de massa seca de raiz quando utilizaram o substrato Plantmax ${ }^{\circledR}$.

Blank et al. (2007) obtiveram maior peso seco de mudas de manjericão quando utilizaram substrato a base de adubo mineral Hortosafra ${ }^{\circledR}$ e esterco de galinha. Segundo Amaro et al. (2013), o ganho em massa está diretamente relacionado com o vigor das estacas após o enraizamento, assim essa característica está em função da maior capacidade de transformação dos tecidos e suprimento das reservas dos tecidos de armazenamento. Costa, Pinto e Bertolucci (2007) trabalharam com Ocimum selloi e constataram que, apesar do comprimento da estaca não ter afetado a porcentagem de sobrevivência e o comprimento da raiz, as mudas obtidas de estacas com $20 \mathrm{~cm}$ apresentaram maior biomassa seca de folhas e raízes.

$\mathrm{O}$ índice de qualidade de Dickson, parâmetro indicador da qualidade das mudas, está apresentado na Figura 3. Notam-se, na Figura 3, valores de 0,7 para o substrato areia lavada e valores abaixo de 0,2 para o substrato fibra de coco. As mudas com IQD menores de 0,2 indicam má qualidade final para ir ao campo e quanto maior o valor de IQD, maior também a qualidade da muda (HUNT, 1990).

De acordo com Fonseca et al. (2002), o índice de qualidade de Dickson é um bom indicador de qualidade, pois leva-se em conta o equilíbrio da distribuição 
da biomassa, mostrando-se um importante parâmetro a ser empregado na avaliação da qualidade de mudas. Pode-se verificar na Figura 3 que os substratos Plantmax ${ }^{\circledR}$ e areia lavada apresentaram os maiores IQD.
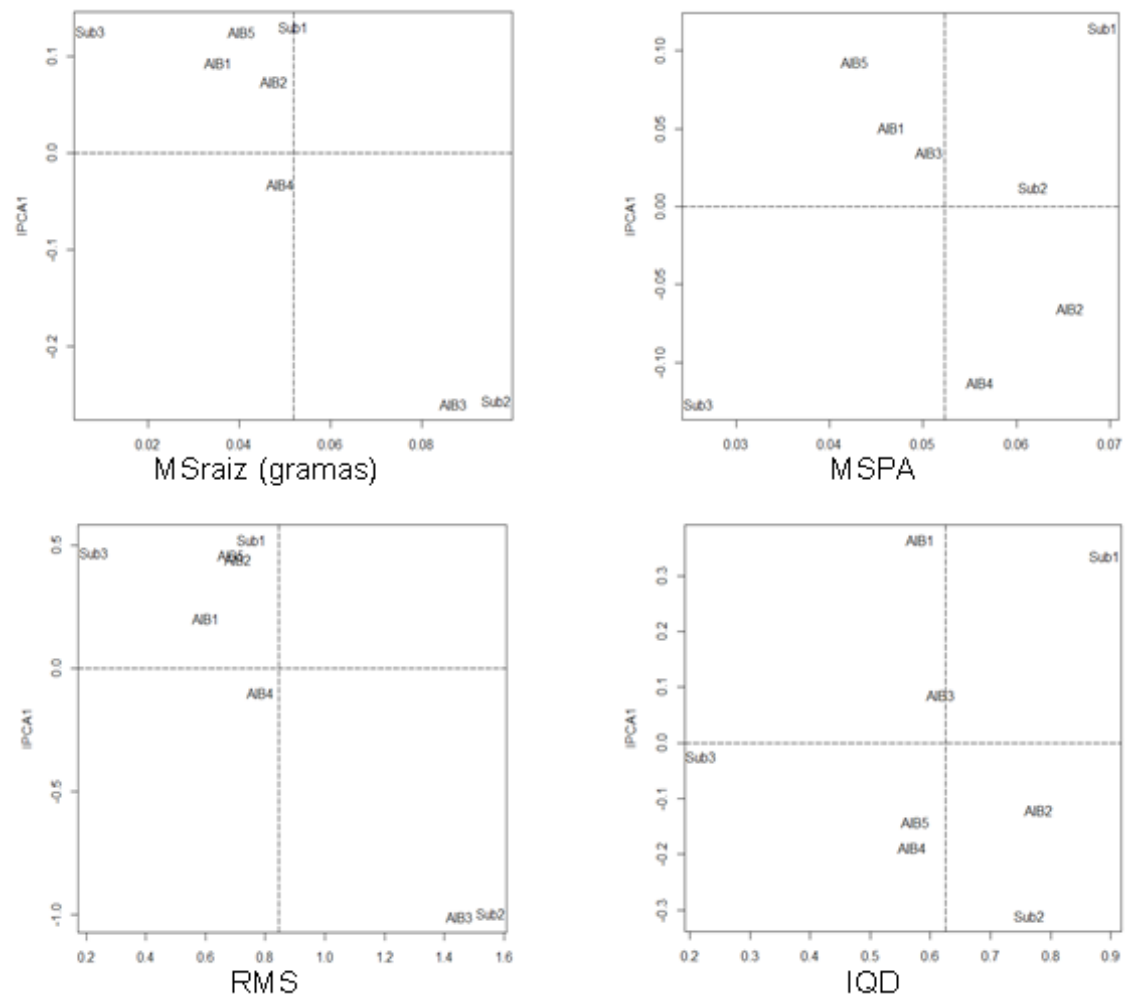

Figura 3. Biplot AMMI1 para dados de MSraiz, MSPA, RMS e IQD, com três substratos (Sub) e cinco níveis de concentrações de ácido indolbutírico (AIB) no Ocimum basilicum L.

A característica herbácea das estacas de Ocimum basilicum L., juntamente com a presença de folhas, promoveu a síntese de auxina endógena nas estacas; dessa forma o tratamento dessas estacas com AIB torna-se uma prática dispensável. Com relação aos substratos, pode-se inferir que a boa aeração e a maior retenção de umidade por parte do substrato Plantmax ${ }^{\circledR}$ resultaram em melhor desenvolvimento radicial de Ocimum basilicum L. No caso da escolha do uso do substrato areia lavada, recomenda-se o tratamento com AIB com a concentração de $2000 \mathrm{mg} \mathrm{L}^{-1}$. 


\section{CONSIDERAÇÕES FINAIS}

A propagação por estaquia de Ocimum basilicum L. pode ser realizada tanto por substrato Plantmax ${ }^{\circledR}$ sem tratamento de ácido indolbutírico, como pelo substrato areia lavada com o tratamento de ácido indolbutírico na concentração de $2000 \mathrm{mg} \mathrm{L}^{-1}$ para a produção de mudas de alta qualidade.

\section{REFERÊNCIAS}

AMARO, H.T.R.; SILVEIRA, J.R.; DAVID, A.M.S.S.; RESENDE, M.A.V.; ANDRADE, J.A.S. Tipos de estacas e substratos na propagação vegetativa da menta (Mentha arvensis L.). Revista Brasileira de Plantas Medicinais, v. 15, p. 313-318, 2013.

BADU-APRAKU, B.; OYEKUNLE, M.K.; OBENG-ANTWI; OSUMAN, A.S.; ADO, S.G.; COULIBAY, N.; YALLOU, C.G.; ABDULAI, M.; BOAKYEWA, G.A.; DIDJEIRA, A. Performance of extra-early maize cultivars based on GGE biplot and AMMI analysis. The Journal of Agricultural Science, v. 150, p. 473-483, 2012.

BORDIN, I.; HIDALGO, P.C.; BÜRKLE, R.; ROBERTO, S.R. Efeito da presença da folha no enraizamento de estacas semilenhosas de porta-enxertos de videira. Ciência Rural, Santa Maria, v. 35, p. 215-218, 2005.

BLANK, A.F.; SILVA, P.A.; ARRIGONI-BLANK, M.F.; SILVA- MANN, R.; BARRETO, M.C.V. Influência da adubação orgânica e mineral no cultivo de manjericão cv. Genovese. Revista Ciência Agronômica, Fortaleza, v. 36, n. 2, p. 175-180, 2005.

BRANT, R.S.; PINTO, J.E.B.P.; ROSA, L.F.; ALBUQUERQUE, C.J.B.; FERRI, P.H.; CORREA, R.M. Crescimento, teor e composição do óleo essencial de melissa cultivada sob malhas fotoconversoras. Ciência Rural, Santa Maria, v. 39, n. 5, p. 1401-1407, 2009.

CARDOSO, C.; YAMAMOTO, L.Y.; PRETI, E.A.; ASSIS, A.M.; NEVES, C.S.V.J.; ROBERTO, S.R. AIB e substratos no enraizamento de estacas de pessegueiro "Okinawa" coletadas no outono. Semina: Ciências Agrárias, v. 32, n. 4, p. 1307-1314, out. 2011. 
COSTA, L.C.B.; PINTO, J.E.B.P.; BERTOLUCCI, S.K.V. Comprimento da estaca e tipo de substrato na propagação vegetativa de atroveran. Ciência Rural, Santa Maria, v. 37, n. 4, p. 1157-1160, 2007.

CUNHA, C.S.M.; MAIA, S.S.S.; COELHO, F.B.M.; FREIRE, A.G. Influência do tipo de estaca e substrato na propagação vegetativa de canelinha-brava (Croton Zehntneri Pax Et Hoffm.). Agropecuária Científica no Semi-Árido, v. 9, p. 24, 2013.

DUTRA, L.F.; KERSTEN, E.; FACHINELLO, J.C. Época de coleta, ácido indol butírico e triptofano no enraizamento de estacas de pessegueiro. Scientia Agrícola, Piracicaba, v. 59, n. 2, p. 327-333, 2002.

EHLERT, P.A.D.; LUZ, J.M.Q.; INNECCO, R. Propagação vegetativa da alfavaca-cravo utilizando diferentes tipos de estacas e substratos. Horticultura Brasileira, v. 22, n. 1, p. 10-13, 2004.

FACHINELLO, J.C.; HOFFMANN, A.; NACHTIGAL, J.C. (Ed.). Propagação de plantas frutíferas. Brasília, DF: Embrapa Informação Tecnológica, 2005. 221p.

FONSECA, É.P.; VALERI, S.V.; MIGLIORANZA, E.; FONSECA, N.A.N.; COUTO, L. Padrão de qualidade de mudas de Trema micrantha (L.) Blume., produzidas sob diferentes períodos de sombreamento. Revista Árvore, Viçosa, MG, v. 26, n. 4, p. 515-523, 2002.

GABRIEL, K.R. The biplot graphic of matrices with application to principal component analysis. Biometrika, London, v. 58, n. 3, p. 453-467, 1971.

GOLLOB, H.F.A statistical model which combines features of factor analytic e analysis of variance. Psychometrika, v. 33, p. 73-115, 1968.

GOMES, J.M. Parâmetros na avaliação da qualidade de mudas de Eucalyptus grandis, produzidas em diferentes tamanhos de tubetes e de dosagens de NPK. 2001. 166f. Tese (Doutorado) - Universidade Federal de Viçosa, MG, 2001.

GOMES, J.M.; COUTO, L.; LEITE, H.G.; XAVIER, A.; GARCIA, S.L.R. Parâmetros morfológicos na avaliação da qualidade de mudas de Eucalyptus grandis. Revista Árvore, v. 26, n. 6, p. 655-664, 2002. 
HARTMANN, H.T.; KESTER, D.E.; DAVIES JUNIOR, F.T.; GENEVE, R.L. Plant propagation: principles and practices. 7. ed. New Jersey: Prentice Hall, 2002. 880p.

HUNT, G.A. Effect of styroblock design and cooper treatment on morphology of conifer seedlings. In: TARGET SEEDLINGS SYMPOSIUM, MEETING OF THE WESTERN FOREST NURSERY ASSOCIATIONS, Roseburg, 1990. Proceedings... Fort Collins: United States Departament of Agriculture, Forest Service, 1990. p. 218-222.

LAVORANTI, O.J. Modelagem AMMI para estudos de interação em modelos estatísticos de efeitos fixos. Colombo: EMBRAPA Florestas, 2004. 7p. (Comunicado Técnico, 124).

LOURENÇO, R.S.; MEDRADO, M.J.S.; FOWLER, J.A.P.; MOSELE, S.H. Influência do substrato no desenvolvimento de mudas de erva-mate (Ilex paraguariensis St. Hil.). Perspectiva, v. 24, n. 88, p. 81-99, 1999.

MATTANA, R.S.; FRANCO, V.F.; YAMAKI, H.O.; MAIA E ALMEIDA, C.I.; MING, L.C. Propagação vegetativa de plantas de pariparoba (Potbomorphe umbellata L.) em diferentes substratos e números de nós. Revista Brasileira de Plantas Medicinais, v. 11, n. 3, p. 325-329, 2009.

MAUAD, M.; FELTRAN, J.C.; CORRÊA, J.C.; DAINESE, R.C.; ONO, E.O.; RODRIGUES, J.D. Enraizamento de estacas de azaléia tratadas com concentrações de ANA em diferentes substratos. Ciência e Agrotecnologia, Lavras, v. 28, p. 771-777, 2004.

MILNER, L. Caracterização, manejo e qualidade de substratos para a produção de plantas. Campinas: Instituto Agronômico, 2002. 122p. (Documento IAC, n. 70).

MOURA, M.C.F.; RIBEIRO, M.C.C.; BENEDITO, C.P.; OLIVEIRA, G.L.; SOARES, S.R.F. Propagação vegetativa de liamba (Vitex agnus castus) por estaquia em diferentes substratos e proporções. Revista Verde, v. 4, n. 3, p. 33-38, 2009.

PACHECO, J.P. Estaquia de Luebea divaricata Mart. (açoita-cavalo). 2007. 84 f. Dissertação (Mestrado em Engenharia Florestal) - Universidade Federal de Santa Maria, RS, 2007. 
PAULUS, D.; VALMORBIDA, R.; TOFFOLI, E.; PAULUS, E.; GARLET, T.M.B. Avaliação de substratos orgânicos na produção de mudas de hortelã (Mentha gracilis $\mathrm{R}$. Br. e Mentha x villosa Huds.). Revista Brasileira de Plantas Medicinais, Botucatu, v. 13, n. 1, p. 90-97. 2011.

PIRES, E.J.P.; BIASI, L.A. Propagação da videira. In: POMMER, C.V. Uva: tecnologia da produção, pós-colheita e mercado. Porto Alegre: Cinco Continentes, 2003. p. 295-350.

R DEVELOPMENT CORE TEAM. A Language and environment for statistical computing. Vienna, Austria: R Foundation for Statistical Computing, 2013.

TAIZ, L.; ZEIGER, E. Fisiologia vegetal. 4. ed. Porto Alegre: Artmed, 2009. 819p.

TELMA, M.F.M. Manejo agroecológico de manjericão (Ocimum basilicum L.). 2011. Dissertação (Mestrado) - Universidade Federal do Recôncavo da Bahia, Cruz das Almas, 2011.

Recebido em: 09 de abril de 2014 Aceito em: 28 de setembro de 2014 